\title{
Design of Instrumentation in Detecting Blood Sugar Levels with Non-Invasive Technique Base on IoT (Internet of Things)
}

\author{
Eko Agus Suprayitno* ${ }^{1}$, Akhmad Setiawan ${ }^{1}$, Rohman Dijaya ${ }^{2}$ \\ ${ }^{1}$ Department of electrical Engineering, Universitas Muhammadiyah Sidoarjo, Sidoarjo, Indonesia \\ ${ }^{2}$ Department of Informatics, Universitas Muhammadiyah Sidoarjo, Sidoarjo, Indonesia \\ *Corresponding author E-mail: eko.agus@umsida.ac.id
}

\begin{abstract}
Diabetes mellitus is a disease with metabolic disorders that result from defects in insulin secretion, which results in hyperglycemia with impaired carbohydrates, fats and body proteins. Diabetes mellitus can be known by measuring blood sugar levels which are generally done by injuring the body (Invasive) for blood. Normal blood sugar values range from $70-200 \mathrm{mg} / \mathrm{dL}$. For people with diabetes mellitus, checking blood sugar is an important thing to do to maintain their body condition. In this study made Instrumentation detection of blood sugar levels non-invasive (does not hurt the body). This study uses the MAX30100 sensor as a non-invasive measure of blood sugar levels, because to determine blood sugar levels is only done by attaching the index finger to the sensor, and does not hurt the fingers. The value of blood sugar levels in this instrumentation is displayed on LCD and Android smartphones. For serial communication, Instrumentation with Android smartphones is done with IoT (Internet Of Things) technology to make it easier for medical officers to monitor the condition of diabetics through remote Android smartphones. From the results of testing Non-invasive blood sugar detection instrumentation with industry standard blood sugar measurement (Invasive), the accuracy of blood sugar readings was $90.3 \%$ with a deviation of 1.2 - $39.6 \mathrm{mg} / \mathrm{dL}$. Tests were carried out on 14 Normal patients and people with diabetes mellitus. Reading distance reading Non-invasive blood sugar detection instrumentation with an Android Smartphone can reach a distance of $823 \mathrm{Km}$ as long as Instrumentation is connected to the internet. Tests have been carried out in several cities including Sidoarjo, North Jakarta, Sidoarjo-Lamongan, SidoarjoKediri.
\end{abstract}

Keywords: Diabetes Mellitus, MAX30100, IoT, NodeMCU

\section{Introduction}

Diabetes mellitus in Indonesia ranks fourth with the largest number of people with diabetes mellitus in the world after India, China and United States. Diabetes mellitus is known to be the highest cause of death in hospital inpatient installations in 2005, namely 3,316 deaths with a percentage of deaths of $7.9 \%$. (World Health Organization (WHO) and International Diabetes Federation (IDF)). WHO estimates that the number of people with diabetes mellitus has increased by $50 \%$ in 2010 , and will double by the next 2025[1]. Non-invasive studies (treatment by not injuring the body) have been carried out to measure blood sugar levels using Nellcor-Ds 100A sensor and blood type determination using LEDs and LDR. Research on blood sugar levels using an ATMega 128 microcontroller to run the sensors, and help display the measurement results on the tool display layer (LCD) [2].

In this study, blood sugar levels were measured with non-invasive techniques (done by not injuring the body) using the MAX30100 sensor. The value of the measurement results will be displayed on the tool display screen (LCD) and smartphone an-droid. Wireless communication between blood sugar detection devices and smartphones is done with the help of the internet, which is commonly called IoT (Iternet Of Things) communication. This is done so that patients who measured their blood sugar can be monitored by a doctor without being limited by distance. This blood sugar level measuring device is made non-invasive (without hurting the body), the measurement is enough to place the finger to the sensor and the results can be seen on the device display or can be seen on a smartphone at a distance of hundreds of kilometers

\section{Method}

System block diagram Blood sugar measuring instrument is shown in Figure 2.1. NodemChu microcontroller is used to control the work of the MAX30100 sensor and to control IoT Communication (Internet of Things) a measuring device for smartphones. MAX30100 sensor is used to get the measurement results of the finger blood sugar level of the patient's finger. The results of the measurement of the patient's blood sugar levels are displayed on the $16 \times 2$ LCD on the measuring instrument and displayed on an Android smartphone. Web Server for IoT communication using Firebase, so that the data produced by measurement can be recorded.

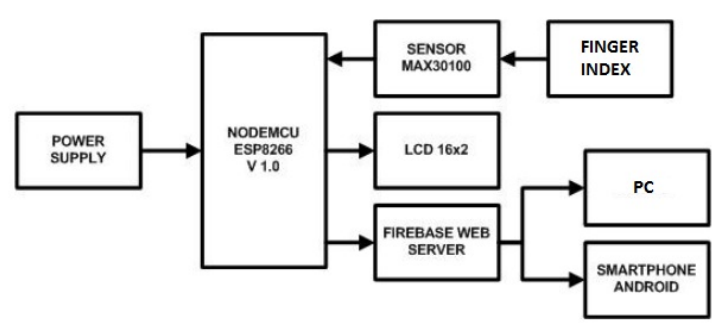

Fig. 1. Block diagram of a system for measuring blood sugar 
Designing a non-invasive blood sugar level measuring device using Max30100 which is integrated with IoT (Internet of Things).

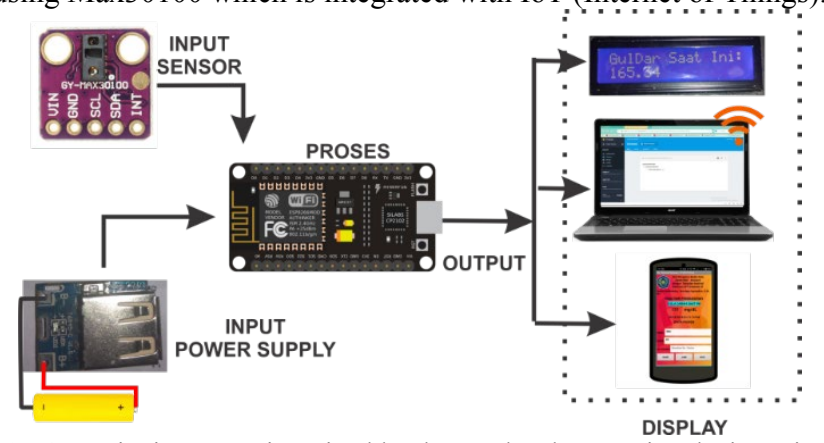

Fig. 2. Designing a non-invasive blood sugar level measuring device using Max30100 which is integrated with IoT (Internet of Things).

Testing of non-invasive blood sugar level measuring devices aims to find out the sensors are operating properly and produce high accuracy. The testing step was carried out by testing the sensors on the index finger with the number of patients tested as many as 14 people, and the tests were repeated 5 times. The value of the measurement results is displayed on the Android Device and Smartphone display. Tests were also carried out on the ability to read the blood sugar level measuring instrument on Android smartphones. Running Android apps are tested on several smartphones to ensure their work reliability.

\section{Results and Discussions}

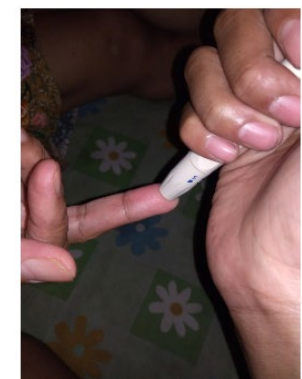

Fig.3. Measurement of blood sugar levels by invasive

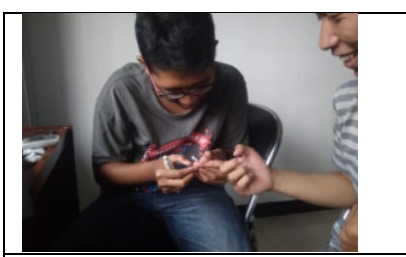

Fig. 5. Invasive Measurement Process

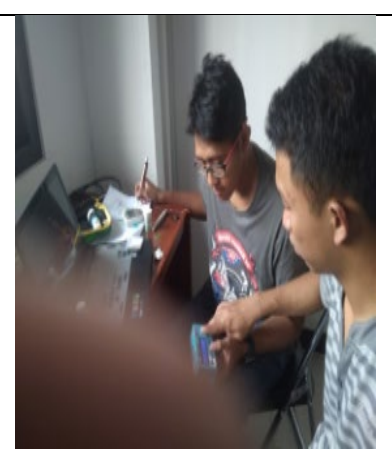

Fig. 7. Non-Invasive Measurement Process

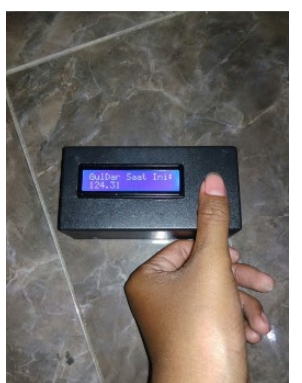

Fig. 4. Non-invasive measurement of blood sugar levels

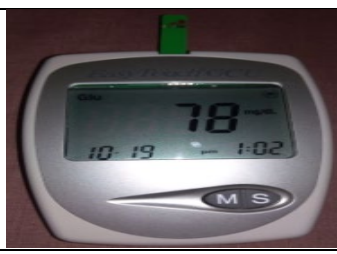

Fig. 6. Invasive standard measurement tool

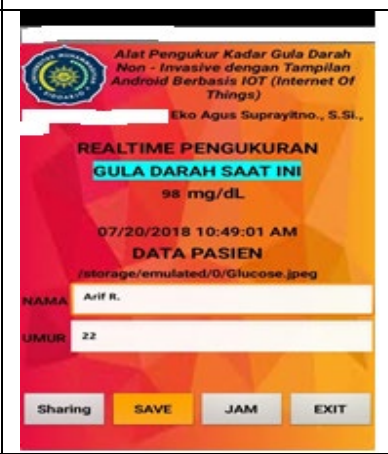

Fig. 8. Android application on Smartphone Non-Invasive measurements
Figure 3 is invasive taking blood sugar levels (injuring the body) by taking blood in the patient. Figure 4 is a Non-Invasive blood sugar level (not injuring the body) by taking blood from the patient. By attaching the index finger to the sensor. Table 1 contains the results of data collection in many patients and carried out as much as five times the data retrieval of each patient. Industry standard tools for measurement of sugar content in this study were used to compare the results of sensor reading of Non-Invasive blood sugar detection devices and their accuracy. In the table shows the results of sensor reading of non-invasive blood sugar measuring instrument (MAX30100) on the standard instrument of the Invasive blood sugar measuring instrument industry, its accuracy reaches $96.7 \%-98.9 \%$ with a standard deviation of $1.2 \mathrm{mg} /$ $\mathrm{dL}-3.6 \mathrm{mg} / \mathrm{dL}$. This shows that the accuracy of non-invasive sugar content measuring instruments is quite good, and its value is stable close to the value of industry standard measuring instruments [3].

Table 1. Results of testing Non-Invasive blood sugar level detection devices

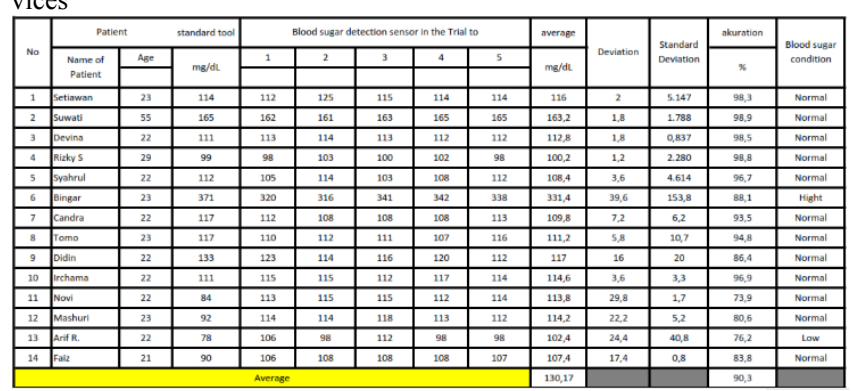

Biologically, high blood sugar levels are caused by a body condition that does not have enough insulin and it causes insulin resistance, which is a hormone released by pancreas [4]. In the pancreas there is an endocrine gland composed of alpha cells, $\beta$, and cells $\mathrm{f}$. In $\beta$ cells are cells that work on high blood sugar levels and the nature of $\beta$ cells lowers blood sugar levels. Damage to the $\beta$ cell causes blood sugar to rise as in the sufferer named Binger who has a value of $371 \mathrm{mg} / \mathrm{dL}$ on a standard device that is legible and on an Android smartphone that reads has a value of $320 \mathrm{mg} / \mathrm{dL}$ with accuracy in measuring $88.1 \%$ and including sugar high blood pressure. Physical factors from different patients can also affect measurement because each patient has a different skin thickness on his finger that affects the penetration of the infrared signal [5]. Another factor may be due to the lack of infrared signals scattered around it and the lack of infrared reflection received by the photodiode[6].

Table 2. Testing ESP8266 as an IoT module for Android smartphones

\begin{tabular}{|c|c|c|c|c|c|c|c|c|c|c|}
\hline \multirow{2}{*}{ No } & \multirow{2}{*}{ smartphone type } & \multirow{2}{*}{$\begin{array}{c}\text { distance } \\
(\mathbf{K m m})\end{array}$} & \multicolumn{5}{|c|}{ Test to } & \multirow{2}{*}{ Average } & \multirow{2}{*}{$\begin{array}{l}\text { Standard } \\
\text { Deviatton }\end{array}$} & \multirow[b]{2}{*}{ Locatton } \\
\hline & & & 1 & 2 & 3 & 4 & 5 & & & \\
\hline 1 & \begin{tabular}{|l|} 
Samsung J7 \\
OS Android 5.1 (Lollipop) \\
CPU Octa-core $1.5 \mathrm{GHz}$ \\
GPU Adreno 405 Mali-TT20MP2 \\
Memory Internal 16GB, RAM \\
1.5GB \\
Wi-Fi 802.11 bign, Wi-Fi Direct, \\
Hotspot
\end{tabular} & 6,6 & 1 & 1 & 1 & 1 & 1 & 1 & 0 & $\begin{array}{c}\text { Wunut- } \\
\text { Balonggabus } \\
\text { Candi }\end{array}$ \\
\hline 2 & \begin{tabular}{|l|} 
Zenfone Go ZC500TG \\
OS Android 5.1 (Lolllpop) \\
CPU Quad-core e.1.GHz \\
GPU Mali-400M22 \\
Memory Internal 8/6GG, RAM \\
2GB \\
Wi-Fi $802.11 \mathrm{~b} / \mathrm{gin}$. Hotspot
\end{tabular} & 99 & 1 & 1 & 1 & 1 & 1 & 1 & 0 & $\begin{array}{c}\text { Wunut } \\
\text { Porong- } \\
\text { Babat } \\
\text { Lamongan }\end{array}$ \\
\hline \multirow[t]{2}{*}{3} & 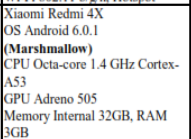 & 823 & 1 & 1 & 1 & 1 & 1 & 1 & 0 & $\mid \begin{array}{c}\text { Candi- } \\
\text { Penjaringan } \\
\text { Jakarta Utars. }\end{array}$ \\
\hline & $\begin{array}{l}\text { Wi-Fi } 802.11 \mathrm{~b} / g \mathrm{~g}, \text { Wi-Fi Direct, } \\
\text { Hotspot }\end{array}$ & 17 & 1 & 1 & 1 & 1 & 1 & 1 & 0 & \begin{tabular}{|c|}
$\begin{array}{c}\text { Candi- } \\
\text { Pondok } \\
\text { Wage Indah }\end{array}$ \\
Wal
\end{tabular} \\
\hline 4 & \begin{tabular}{|l|} 
Samsung Galaxy S5 \\
OS Android 4.42 .2 (Kittat) \\
CPU Quad-core $2.5 \mathrm{GHz}$ Krait \\
400 \\
GPU Adreno 330 \\
Memory Internal 1632GB, RAM \\
2GB \\
Wi-Fi 802.11 ab/g/gn/ac, Dual- \\
band, Wi-Fi Direct, Hotspot- \\
\end{tabular} & 107 & 1 & 1 & 1 & 1 & 1 & 1 & 0 & $\begin{array}{c}\text { Candi- } \\
\text { Banjaran } \\
\text { Kediri }\end{array}$ \\
\hline
\end{tabular}




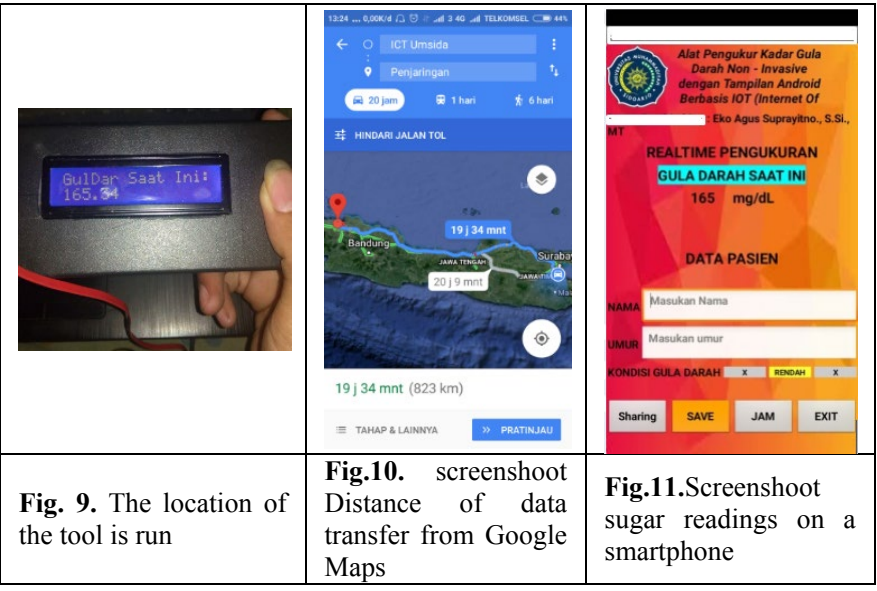

In Table 4 To test ESP8266 as an IoT communication module (Internet of Things), shows the results of the analysis that the value of Blood Sugar levels will be sent to the smartphone according to the values in the blood sugar level detection device. Blood sugar level detection devices must be connected to the internet network so that data communication with smartphones is smooth. Samsung $\mathrm{J} 7$ type smartphone uses a $3 \mathrm{G}$ signal connection network, so data transmission is disrupted because the $3 \mathrm{G}$ signal on the internet is unstable. This is different from the 4G LTE signal. In this network, the data transfer is very stable. Therefore, high data rates are needed so that communication with smartphones runs smoothly.

\section{Conclusion}

Instrumentation for detecting blood sugar levels non-invasively (not injuring the body) is made using the MAX30100 sensor and the Programming Algorithm on the Arduino IDE. The measurement of noninvasive blood sugar levels in this study was done by attaching the index finger to the sensor, and did not have to hurt the fingers until blood appeared. The value of blood sugar levels in this instrumentation is displayed on LCD and Android smartphones by utilizing IOT serial communication (Internet of Things) to make it easier for medical officers to monitor the condition of diabetics through remote Android smartphones. test results Non-invasive blood sugar detection instrumentation with industry standard blood sugar measuring instrument (Invasive) resulted in an accuracy of $90.3 \%$ blood sugar reading with a deviation value of $1.2-39.6 \mathrm{mg} / \mathrm{dL}$. Tests were carried out on 14 Normal patients and people with diabetes mellitus. Reading distance reading Non-invasive blood sugar detection instrumentation with an Android Smartphone can reach a distance of $823 \mathrm{Km}$ as long as Instrumentation is connected to the internet. Tests have been carried out in several cities including Sidoarjo, North Jakarta, Sidoarjo-Lamongan, Sidoarjo-Kediri.

\section{Acknowledgement}

The researchers would like to say thank you to the Universitas Muhammadiyah Sidoarjo, for funded this article publication charges.

\section{References}

[1] E. Hidayanto, H. Sutanto, and Z. Arifin, "Design of Non-Invasive Glucometer using Microcontroller ATMega-8535," J. SAINS DAN Mat., vol. 23, no. 3, pp. 78-83, Jul. 2015.

[2] D. Paramita, "Detection Equipment blood group and Measuring Blood Sugar Levels In Non Invasive Blood-Based Microcontroller ATMega 128," Semarang, 2012.

[3] N. F. Hikmah, A. Arifin, T. A. Sardjono, and E. A. Suprayitno, "A signal processing framework for multimodal cardiac analysis," in 2015 International Seminar on Intelligent Technology and Its
Applications, ISITIA 2015 - Proceeding, 2015.

[4] E. A. Suprayitno, R. Hendradi, and A. Arifin, "Analisa Sinyal Electrocardiography dan Menggunakan Continuous Wavelet Transform," in The 6th Electrical Power, Electronics, Communications, Controls, and Informations Seminar, 2012.

[5] S. K. Vashist, "Non-invasive glucose monitoring technology in diabetes management: A review," Anal. Chim. Acta, vol. 750, pp. 16-27, Oct. 2012.

[6] I. Gabriely, R. Wozniak, M. Mevorach, J. Kaplan, Y. Aharon, and H. Shamoon, "Transcutaneous glucose measurement using nearinfrared spectroscopy during hypoglycemia," Diabetes Care, 1999. 